\title{
Association between obesity, common chronic diseases and health promoting lifestyle profiles in Hong Kong adults: a cross-sectional study
}

Yan Sin Leung, Jack Jock Wai Lee, Maria Ming Po Lai, Chole Kei Ming Kwok and Ka Chun Chong* (D)

\begin{abstract}
Background: Recent surveys revealed that the health status of many people from Hong Kong is far from ideal. Although non-communicable diseases are largely preventable, few relevant health promotion and disease prevention programs are available. Thus, we assessed the health indicators of Chinese adults in Hong Kong to investigate the relationship between obesity, common chronic diseases, and health-promoting lifestyle profiles to provide inspirations for decision makers in formulating targeted disease prevention and health management programs.
\end{abstract}

Methods: This is a secondary analysis of a data set of 270 community-dwelling Hong Kong adults who were within the eligible age range between 18 and 80 years without eye diseases that affect retinal photographs. The study exposure variable, health-promoting lifestyle profiles, was measured using the Health-Promoting Lifestyle Profile II (HPLP-II) questionnaire. The primary outcome variable, obesity, was defined using body mass index and waist-hip ratio. The secondary study outcome, estimated chronic diseases, including of anemia, chronic kidney disease, and cardiovascular disease, were estimated using automatic retinal image analysis from the retinal images. Data were analyzed using tests of proportion, the independent sample t-tests, Welch's t-test, and binary logistic regression models.

Results: All HPLP-\|l subscales had positive responses ( $\geq 2.5$ ). Significant differences were noted between men and women in the health responsibility and nutrition subscales (Health Responsibility: $p=0.059$; Nutrition: $p=0.067$ ). Regression models revealed that nutrition (adjusted odds ratio $[A O R]=0.41 ; p=0.017$ ), physical activity ( $A O R=0.50$; $p=0.015)$, interpersonal relations ( $A O R=2.14 ; p=0.016)$, and stress management $(A O R=2.07 ; p 0.038$ ) were associated with obesity; while spiritual growth $(A O R=0.24 ; p=0.077)$ and interpersonal relations $(A O R=5.06 ; p$ 0.069) were associated with estimated chronic kidney disease.

(Continued on next page)

\footnotetext{
* Correspondence: marc@cuhk.edu.hk

Jockey Club School of Public Health and Primary Care, The Chinese

University of Hong Kong, Hong Kong, China
}

(c) The Author(s). 2020 Open Access This article is licensed under a Creative Commons Attribution 4.0 International License, which permits use, sharing, adaptation, distribution and reproduction in any medium or format, as long as you give appropriate credit to the original author(s) and the source, provide a link to the Creative Commons licence, and indicate if changes were made. The images or other third party material in this article are included in the article's Creative Commons licence, unless indicated otherwise in a credit line to the material. If material is not included in the article's Creative Commons licence and your intended use is not permitted by statutory regulation or exceeds the permitted use, you will need to obtain permission directly from the copyright holder. To view a copy of this licence, visit http://creativecommons.org/licenses/by/4.0/ The Creative Commons Public Domain Dedication waiver (http://creativecommons.org/publicdomain/zero/1.0/) applies to the data made available in this article, unless otherwise stated in a credit line to the data. 
(Continued from previous page)

Conclusions: Improving health behaviors may control or alleviate the prevalence of obesity and chronic kidney disease. These findings could arouse concern about lifestyle behaviors and promote self-assessment of healthpromoting lifestyles to the general public. The study also provided new insights into the relationship between the HPLP-II and other common chronic diseases that warrant further study.

Keywords: HPLP-II, Lifestyle, Chronic disease, Obesity, Chinese adults, ARIA

\section{Background}

Non-communicable diseases (NCDs) are not only major causes of ill-health and disability but also a top killer worldwide, accounting for $71 \%$ of deaths annually [1]. The incidence and prevalence of chronic diseases in Hong Kong are showing worrying trends. In the Population Health Survey (PHS) 2017, 50\% of participants were classified as overweight or obese [2]. Moreover, in the Thematic Household Survey Report No. 63, nearly one-third of the Hong Kong population $(1,983,200$ persons, $28.4 \%)$ was diagnosed with chronic diseases [3]. In particular, a large proportion of this population has hypertension (13.7\%), followed by high cholesterol (7.2\%), diabetes (5.8\%) and coronary heart disease (2.1\%) [3].

NCDs are largely preventable and highly manageable by modification of the associated risk factors, many of which are included in lifestyle, such as physical inactivity [4]. Therefore, health promotion and disease prevention strategies should be developed to alleviate this situation. Although several studies have revealed an association between lifestyle and certain diseases such as type 2 diabetes $[5,6]$ and stage 1 hypertension $[7,8]$, most cover only single aspect of health-promoting lifestyles, mainly physical activity and nutrition intake [5-8]. Compared to these onesided estimations, the Health-Promoting Lifestyle Profile II (HPLP-II) provides a multidimensional assessment of health-promoting lifestyle. By elucidating any relationships of the prevalence of obesity and estimated common chronic diseases, including estimated anemia, estimated chronic kidney disease (CKD), and high cardiovascular disease (CVD) risk with participants' HPLP-II and imbalances in subscales, particular dimensions and communities that require focus can be defined. Additionally, the HPLP-II is easy to assess; self-assessment and attempts at change can be done by the general public.

The purposes of study were to (1) investigate if there are any relationships between obesity and the three estimated common chronic diseases (anemia, CKD, and high CVD risk) and the HPLP-II in Hong Kong adults and (2) determine if there are any significant differences in lifestyle between individuals with and without estimated chronic diseases.

\section{Methods}

\section{Study design and participants}

This study was a secondary analysis of a data set in which the HPLP-II was considered an exposure variable, while obesity and estimated chronic disease risks were the two outcome variables. Data were obtained from a lifestyle study carried out by the Chinese University of Hong Kong.

The original study's participants were recruited voluntarily through advertisements posted on the school campus. Eligible participants were community-dwelling Chinese adults aged 18-80years without eye diseases that affect retinal photographs. Participants were asked to complete the HPLP-II questionnaire [9], and on-site tests were conducted to record demographic variables (age, sex, etc.), perform body measurements, and take retinal images. Written informed consent were obtained from all participants before the start of the study.

\section{Sample size calculation}

We adopted the sample size calculation approach by Peduzzi et al. (1996) for logistic regression analysis, in which the sample size was calculated assuming $p$, the proportion of the population with chronic diseases, to be $28.4 \%$ [3] and the number of predictors, $K$, to be six, equaling the number of subscales in the HPLP-II. Based on the above assumptions and eq. $N=10 K / p$, a sample size of 264 was needed assuming $20 \%$ of the surveys were incomplete [10].

\section{Data collection \\ HPLP-Il questionnaire}

Although many instruments are available for health behaviors measurement, most of them cover only a single aspect of health-promoting lifestyles [11]. Compared to these tools, the HPLP-II provides a multidimensional assessment of health- promoting lifestyle with high reliability and validity [12].

HPLP-II is a 52-item questionnaire comprising a total scale and six subscales scores in the six theorized dimensions, including health responsibility, physical activity, nutrition, spiritual growth, interpersonal relations, and stress management. Each item in the questionnaire is responded to using a four-point Likert scale scored as 1, 2, 3, and 4 for responses Never $(\mathrm{N})$, Sometimes $(\mathrm{S})$, 
Often (O), and Routinely (R), respectively [9]. In accordance with a previous study, responses with a mean score of $\geq 2.50$ were considered positive [13].

\section{Obesity and chronic disease risks}

The first study outcome, obesity, was defined by body mass index (BMI) and waist-hip ratio (WHR) calculated using clinical data measured during the on-site physical assessment; the second outcome variable, estimated chronic diseases, was estimated using automatic retinal image analysis (ARIA).

On-site physical assessment for obesity We collected physical data including age, sex, height, weight, waist circumference, and hip-circumference during the on-site physical assessment. Obesity indicators, WHR and BMI [14], were calculated using physical data. BMI was calculated by weight $(\mathrm{kg}) /(\text { height }[\mathrm{m}])^{2}$ where the weights and heights measurements of the participants were recorded to the nearest $0.1 \mathrm{~kg}$ and $0.01 \mathrm{~m}$, respectively. Using the Asian-specific obesity classification system, participants were categorized into the underweight/normal weight group $\left(<23 \mathrm{~kg} / \mathrm{m}^{2}\right)$ and the overweight/obese group $\left(\geq 23 \mathrm{~kg} / \mathrm{m}^{2}\right)$ [15]. WHR was measured as waist circumference $(\mathrm{cm}) /$ hip circumference $(\mathrm{cm})$. Overweight/obese was defined as a WHR $>0.90$ and $>0.85$ for men and women, respectively $[16,17]$.

ARIA to estimate chronic disease A beta-testing approach of the ARIA method was used to estimate the chronic disease parameters, including total cholesterol (TC), low-density lipoprotein cholesterol (LDL-C), highdensity lipoprotein cholesterol (HDL-C), hemoglobin, and estimated glomerular filtration rate (eGFR), to determine the estimated chronic disease for estimated anemia, estimated CKD, and estimated CVD risks. The working fundamentals of ARIA are based on retinal characteristics. The analysis extracts retinal risk factors related to cardiovascular changes from participant's retinal images.

To estimate chronic diseases, method has been developed [18] for the evaluation of cerebral vessel conditions by analyzing retinal photographs pixel by pixel and produce measurements on retinal vascular parameters such as exudates, hemorrhages, and new vessels to achieve an overall evaluation of the parameters. Finally, the retinal information is converted using a beta-testing methodology into quantifiable and analyzable indicators, including TC, LDL-C, HDL-C, hemoglobin, and eGFR. The detailed procedure of ARIA can be found in Zee [18].

Retinal images were taken using Digital Non-Mydriatic Retinal Cameras CR-2 (Canon U.S.A., Inc.).
Determination of the risks of chronic diseases Based on the estimated disease parameters by ARIA, the chronic diseases in the study population were estimated and then classified using the International Classification of Diseases.

Risk of anemia Subjects with estimated hemoglobin levels $<11.0 \mathrm{~g} / \mathrm{dL}$ were considered anemic [19].

Risk of CKD Estimated CKD is suggested as a urinary albumin-to-creatinine ratio of $>30 \mathrm{mg} / \mathrm{g}$ or an eGFR of $<60 \mathrm{~mL} / \mathrm{min} / 1.73 \mathrm{~m}^{2}[20,21]$.

Risk of CVD The ratio of estimated TC and estimated HDL-C (TC/HDL-C), also known as the atherogenic or Castelli index, is a reliable indicator of CVD risk [22]. A high TC/HDL-C ratio indicates greater vascular risk, which may due to an increase in the atherogenic component or a decrease in the anti-atherosclerotic trait [23]. The cutoff levels of the TC/HDL-C ratio for the high risk of cardiovascular events are suggested to be $>5.0$ for men and $>4.5$ for women [24].

\section{Statistical analysis}

The proportion test was used to compare the prevalence of estimated chronic diseases in the study population versus population data in Hong Kong to check for representativeness. An independent sample t-test was used to identify any association between obesity, the estimated chronic diseases, and a health-promoting lifestyle, while Welch's t-test was used for variables with unequal variances. Binary logistic regression models were built to describe the patterns of association while controlling for potential confounding variables, including age and sex, in all models. The effect of explanatory variables on the response was evaluated by model parameters. The backward selection was used to obtain the final regression model.

The alpha level $(\alpha)$ was set at 0.05 , and $p$-values smaller than $\alpha$ were considered statistically significant. Since this was an exploratory study, $p$-values smaller than 0.1 were considered marginally significant to provide a more conservative discussion about the generated statistics.

All data were analyzed using the Statistical Package for Social Sciences, version 24 (SPSS, IBM Corp., Armonk, NY).

\section{Results}

\section{Sample characteristics}

A total of 270 Chinese adults in Hong Kong were included. Demographic information and the prevalence of obesity and estimated chronic diseases for the study sample are presented in Table 1 . Of the 270 
Table 1 Demographic characteristics and the prevalence of obesity and chronic diseases of the sample $(n=270)$

\begin{tabular}{|c|c|c|}
\hline & $\mathbf{N}$ & Percentage \\
\hline Age, years (mean $\pm S D$ ) & \multicolumn{2}{|c|}{$59.61 \pm 1.15$} \\
\hline \multicolumn{3}{|l|}{ Sex } \\
\hline Male & 56 & 20.7 \\
\hline Female & 214 & 79.3 \\
\hline \multicolumn{3}{|l|}{ Overweight or obese } \\
\hline 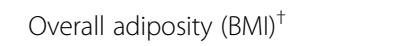 & 147 & 54.4 \\
\hline Abdominal adiposity $(\mathrm{WHR})^{\dagger}$ & 140 & 51.9 \\
\hline \multicolumn{3}{|l|}{ Estimated Chronic diseases } \\
\hline Anemia $^{\dagger}$ & 68 & 25.2 \\
\hline Chronic kidney disease $^{\dagger}$ & 28 & 10.4 \\
\hline High cardiovascular disease risk ${ }^{\dagger}$ & 32 & 11.9 \\
\hline \multicolumn{3}{|c|}{$\begin{array}{l}\text { TFor BMI, a 'Yes' response referred to participants with a BMI } \geq 23 \mathrm{~kg} / \mathrm{m}^{2} \text {; for } \\
\text { WHR, 'Yes' was defined as a WHR }>0.90 \text { and }>0.85 \text { for men and women, } \\
\text { respectively; for estimated anemia, subjects with a hemoglobin level }<11.0 \mathrm{~g} / \\
\mathrm{dL} \text { were considered in the 'Yes' group; for estimated chronic kidney disease, a } \\
\text { 'Yes' response was defined as an eGFR }<60 \mathrm{~mL} / \mathrm{min} / 1.73 \mathrm{~m} \mathrm{~m}^{2} \text {; for Risk of } \\
\text { cardiovascular disease, individuals with a estimated TC/HDL-C ratio }>5.0 \text { for } \\
\text { men and }>4.5 \text { for women were categorized into the "high-risk" group in the } \\
\text { table, while the others belonged to the "average-risk" group. } \\
S D \text { standard deviation, BMI body mass index, WHR waist-hip ratio, eGFR } \\
\text { estimated glomerular filtration rate, TC/HDL-C total cholesterol/high-density } \\
\text { lipoprotein cholesterol }\end{array}$} \\
\hline
\end{tabular}

respondents, 56 (20.7\%) were male, and 214 (79.3\%) were female. The participants' age ranged from 24 to 79 years, with a mean age of 59.61 years. More than half of the participants were overweight or obese, in particular, $54.4 \%$ had overall obesity and $51.9 \%$ had central obesity. The prevalence of estimated anemia and estimated CKD was 25.2 and $10.4 \%$, respectively, while $11.9 \%$ had a higher risk of CVD.

\section{Variations in HPLP-II scores within sex, obesity, and chronic diseases categories}

As shown in Table 2, the mean scores for all HPLP-II dimensions indicated positive responses $(\geq 2.5)$. The highest values were seen in the spiritual growth and interpersonal relations subscales with the same score of 2.78 ( \pm 0.53 for $S G$ and \pm 0.47 for IR), while the lowest was in the physical activity sub-dimension $(2.50 \pm 0.58)$.

Both sexes had an overall score of 2.67 ( \pm 0.41 for women and \pm 0.36 for men). Women had significantly higher scores for health responsibility $(p=0.059)$ and nutrition $(p=0.067)$ than men. Conversely, their scores for physical activity, spiritual growth, interpersonal relations, and stress management were lower than for men; however, the differences were not significant.

Regarding the obesity outcomes, BMI and WHR, no significant differences were noted between the normal and overweight/obese subjects in all the HPLP-II dimensions. Overall, HPLP-II scores of overweight/obese respondents were generally greater than or equal to that of normal weight respondents. The overweight/obese group defined by BMI reported higher scores in all HPLP-II subscales than the normal-weight group except for physical activity and nutrition. Similarly, participants with a WHR corresponding to the overweight/obese category claimed to have higher or equal scores in all dimensions except health responsibility and physical activity.

Meanwhile, for the estimated chronic disease outcomes, the study revealed that patients with estimated chronic diseases generally had lower HPLP-II scores than those without chronic diseases; however, the difference was not significant (Table 2).

\section{Predictive power of HPLP-II subscales for obesity and estimated chronic diseases}

Table 3 summarizes the results of the final regression models. After controlling for relevant variables, the results of the logistic regression model showed that nutrition and interpersonal relations were significant independent predictors of BMI $(p=0.017$ and 0.016, respectively). People with a higher score in the nutrition subscale (adjusted odds ratio $[\mathrm{AOR}]=0.41,95 \%$ confidence interval $[\mathrm{CI}]=0.23-0.86$ ) were more likely to have a lower BMI, while 1-unit increased in interpersonal relations resulted in a 0.76 increase in $\mathrm{BMI}(\mathrm{AOR}=2.14$, 95\% CI $=1.15-3.96$ ).

The multivariate analysis for WHR revealed a significant association between stress management with WHR $(p=$ $0.038)$. A higher score in stress management $(\mathrm{AOR}=2.07$, $95 \% \mathrm{CI}=1.04-4.14)$ was associated with a higher WHR, while participants with a higher score in physical activity $(\mathrm{AOR}=0.50,95 \% \mathrm{CI}=0.28-0.87)$ were significantly more likely to have a lower WHR $(p=0.015)$.

The results of the binary regression model showed that spiritual growth $(p=0.077)$ and interpersonal relations $(p=0.069)$ were significant predictors of estimated CKD. People with a higher score in the interpersonal relations subscale (AOR $=5.06,95 \% \mathrm{CI}=0.88-28.98$ ) were more likely to have estimated CKD, while a higher score in spiritual growth $(\mathrm{AOR}=0.24,95 \% \mathrm{CI}=0.05-1.17)$ was negatively associated with estimated CKD.

No significant predictive power for HPLP-II indicators regarding estimated anemia and CVD risk was found (all $p$-values $>0.10$ ).

\section{Discussion}

The study investigated the relationship between obesity, estimated common chronic diseases and the HPLP-II. Overall, the results revealed a significant association of obesity, and estimated CKD, the two common chronic diseases, with HPLP-II. Respondents with estimated chronic diseases had lower HPLP-II scores than healthy individuals; however overweight/obese individuals scored higher than or equal to the normal-weight participants. 
Table 2 HPLP-II dimensions for all respondents (mean \pm SD)*

\begin{tabular}{|c|c|c|c|c|c|c|c|}
\hline \multicolumn{8}{|l|}{ Categories } \\
\hline & OS & HR & PA & NT & SG & IR & SM \\
\hline Individual average & $2.67 \pm 0.40$ & $2.51 \pm 0.48$ & $2.50 \pm 0.58$ & $2.77 \pm 0.44$ & $2.78 \pm 0.53$ & $2.78 \pm 0.47$ & $2.66 \pm 0.47$ \\
\hline \multicolumn{8}{|l|}{ Sex } \\
\hline Female & $2.67 \pm 0.41$ & $2.54 \pm 0.49$ & $2.48 \pm 0.57$ & $2.79 \pm 0.43$ & $2.77 \pm 0.55$ & $2.78 \pm 0.48$ & $2.64 \pm 0.48$ \\
\hline Male & $2.67 \pm 0.36$ & $2.40 \pm 0.43$ & $2.60 \pm 0.62$ & $2.67 \pm 0.45$ & $2.83 \pm 0.42$ & $2.79 \pm 0.41$ & $2.72 \pm 0.44$ \\
\hline$p$-value & 0.984 & 0.059 & 0.152 & 0.067 & 0.388 & 0.828 & 0.279 \\
\hline \multicolumn{8}{|c|}{ Overweight or obese - overall adiposity (BMI) } \\
\hline Yes & $2.67 \pm 0.41$ & $2.51 \pm 0.49$ & $2.48 \pm 0.59$ & $2.74 \pm 0.41$ & $2.80 \pm 0.57$ & $2.82 \pm 0.46$ & $2.67 \pm 0.52$ \\
\hline No & $2.66 \pm 0.38$ & $2.50 \pm 0.47$ & $2.53 \pm 0.57$ & $2.80 \pm 0.47$ & $2.75 \pm 0.47$ & $2.74 \pm 0.47$ & $2.64 \pm 0.41$ \\
\hline$p$-value & 0.840 & 0.865 & 0.518 & 0.219 & 0.407 & 0.172 & 0.676 \\
\hline \multicolumn{8}{|c|}{ Overweight or obese - abdominal adiposity (WHR) } \\
\hline Yes & $2.67 \pm 0.43$ & $2.47 \pm 0.50$ & $2.47 \pm 0.60$ & $2.77 \pm 0.42$ & $2.79 \pm 0.58$ & $2.78 \pm 0.49$ & $2.69 \pm 0.51$ \\
\hline No & $2.67 \pm 0.36$ & $2.55 \pm 0.46$ & $2.53 \pm 0.56$ & $2.77 \pm 0.45$ & $2.77 \pm 0.46$ & $2.78 \pm 0.44$ & $2.62 \pm 0.43$ \\
\hline$p$-value & 0.890 & 0.199 & 0.391 & 0.952 & 0.700 & 0.971 & 0.190 \\
\hline \multicolumn{8}{|l|}{ Estimated anemia } \\
\hline Yes & $2.66 \pm 0.41$ & $2.47 \pm 0.51$ & $2.54 \pm 0.62$ & $2.74 \pm 0.44$ & $2.75 \pm 0.53$ & $2.75 \pm 0.45$ & $2.68 \pm 0.51$ \\
\hline No & $2.67 \pm 0.39$ & $2.52 \pm 0.47$ & $2.49 \pm 0.57$ & $2.78 \pm 0.43$ & $2.79 \pm 0.53$ & $2.79 \pm 0.47$ & $2.65 \pm 0.46$ \\
\hline$p$-value & 0.760 & 0.430 & 0.582 & 0.576 & 0.579 & 0.594 & 0.666 \\
\hline \multicolumn{8}{|c|}{ Estimated chronic kidney disease } \\
\hline Yes & $2.63 \pm 0.36$ & $2.52 \pm 0.42$ & $2.41 \pm 0.48$ & $2.79 \pm 0.41$ & $2.67 \pm 0.48$ & $2.76 \pm 0.47$ & $2.62 \pm 0.53$ \\
\hline No & $2.67 \pm 0.40$ & $2.51 \pm 0.49$ & $2.51 \pm 0.59$ & $2.77 \pm 0.44$ & $2.79 \pm 0.53$ & $2.78 \pm 0.47$ & $2.66 \pm 0.47$ \\
\hline$p$-value & 0.611 & 0.847 & 0.353 & 0.816 & 0.261 & 0.807 & 0.678 \\
\hline \multicolumn{8}{|c|}{ Estimated cardiovascular disease } \\
\hline High risk & $2.65 \pm 0.41$ & $2.54 \pm 0.53$ & $2.41 \pm 0.59$ & $2.69 \pm 0.44$ & $2.75 \pm 0.54$ & $2.80 \pm 0.50$ & $2.67 \pm 0.51$ \\
\hline Average risk & $2.67 \pm 0.39$ & $2.50 \pm 0.47$ & $2.51 \pm 0.58$ & $2.78 \pm 0.44$ & $2.78 \pm 0.52$ & $2.78 \pm 0.47$ & $2.65 \pm 0.47$ \\
\hline$p$-value & 0.759 & 0.670 & 0.335 & 0.312 & 0.768 & 0.797 & 0.876 \\
\hline
\end{tabular}

"t-test of the HPLP-II dimensions for participants with and without chronic diseases. All responses were reported as means \pm SD HPLP-Il Health-Promoting Lifestyle Profile II, SD standard deviation, OS overall HPLP-Il score, HR Health Responsibility, PA Physical Activity, NT Nutrition, SG Spiritual Growth, IR Interpersonal Relations, SM Stress Management

The finding also showed a sex-difference trend in the health responsibility and nutrition subscales of the HPLP-II. No significant differences were observed between the prevalence of overall obesity, anemia and chronic kidney disease in the study sample and the general population (Additional file 1).

Our regression models showed that HPLP-II subscales contributed to the prediction of obesity and estimated CKD. Among the obesity outcomes, physical activity and nutrition intake appeared to be protective factors for obesity. Persons with better nutrition knowledge and dietary intake (i.e., higher score for Nutrition) or more physically active tended to have a lower risk for overweight/obesity than those who scored lower in these subitems. The results were consistent with previous research that reported beneficial effects of healthy dietary behavior and a more active lifestyle on weight control
[11, 25-27]. Conversely, better stress management and interpersonal relations were associated with a higher probability of obesity. These results seem to partially contradict the previous findings that healthy social relationships would have beneficial effects on obesity [28], while stress was positively correlated with obesity [29, 30]. We found an inverted U-shaped relationship between stress management and interpersonal relations and the obesity index using curve estimation (Additional files 2 and 3). As BMI increased, the interpersonal relations score increased; however, the rise in the interpersonal relations score was only to the point of a BMI around $23 \mathrm{~kg} / \mathrm{m}^{2}$, the borderline of normal weight, beyond which an increase in BMI led to a reduction in the interpersonal relations score (Additional file 2). A similar result was found regarding the relationship between stress management and WHR (Additional file 3). Our 
Table 3 Logistic regression outcomes of obesity and chronic disease risks with HPLP-II subscales as predictors

\begin{tabular}{llll}
\hline Categories & AOR & $\mathbf{9 5 \%}$ Cl & $\boldsymbol{p}$-value \\
\hline Overweight or obese & & & \\
Overall adiposity (BMI) & & & \\
IR & 2.14 & 1.15 to 3.96 & 0.016 \\
NT & 0.41 & 0.23 to 0.86 & 0.017 \\
Age & 1.04 & 1.01 to 1.07 & 0.009 \\
Abdominal adiposity (WHR) & & & \\
PA & 0.50 & 0.28 to 0.87 & 0.015 \\
SM & 2.07 & 1.04 to 4.14 & 0.038 \\
Estimated HDL-C & 1.67 & 1.01 to 2.75 & 0.046 \\
Age & 1.06 & 1.03 to 1.10 & $<0.001$ \\
Estimated anemia & & & \\
Sex (ref. Female) & 3.33 & 1.58 to 7.00 & 0.002 \\
Estimated TC & 0.61 & 0.49 to 0.76 & $<0.001$ \\
Estimated HDL-C & 0.44 & 0.23 to 0.84 & 0.012 \\
Estimated LDL-C & 0.63 & 0.50 to 0.80 & $<0.001$ \\
Estimated chronic kidney disease & & \\
SG & 0.24 & 0.05 to 1.17 & 0.077 \\
IR & 5.06 & 0.88 to 28.98 & 0.069 \\
Estimated HDL-C & 0.11 & 0.04 to 0.30 & $<0.001$ \\
Estimated hemoglobin & 0.48 & 0.34 to 0.67 & $<0.001$ \\
\hline
\end{tabular}

HPLP-II Health-Promoting Lifestyle Profile II, AOR adjusted odds ratio, Cl confidence interval, $B M I$ body mass index, NT Nutrition, IR Interpersonal relations, WHR waist-hip ratio, PA Physical activity, SM Stress management, LDL-C low-density lipoprotein cholesterol, TC total cholesterol, HDL-C highdensity lipoprotein cholesterol; SG, Spiritual growth

results partially support previous findings and emphasize the significance of stress management and interpersonal relations for obesity.

The regression model of estimated CKD revealed a negative correlation between spiritual growth and the risk of CKD, and a positive correlation between estimated CKD and interpersonal relations. Some studies have determined the spiritual needs of patients with CKD regarding their treatment plans [31, 32]. However, studies of spiritual growth and interpersonal relations in the context of the risk of CKD are limited. Our exploratory results provide a potential research topic for further investigation on the role of spiritual well-being and interpersonal relations in the development of CKD.

Our study was unable to find a significant relationship between lifestyle, estimated anemia, and the risk of CVD. Studies that have investigated the predictive power of HPLP-II for chronic diseases are lacking. Therefore, further studies on other common chronic diseases, such as hypertension and diabetes, are recommended. The regression model of anemia also provided some new insights, i.e., the serum lipid profile including TC, HDL-C, and LDL-C was significantly different between anemic and non-anemic individuals [33]. Studies that investigate the relationship between cholesterol and anemia are recommended to determine the underlying mechanisms of this finding.

Apart from the results of the regression model, the finding that the HPLP-II scores of healthy participants tended to be higher than those of participants with chronic diseases is supported by the studies of Cao et al. and Thanavaro et al. [34, 35]. An explanation for this finding is that individuals with higher scores are likely to possess positive health behaviors which are inversely correlated with obesity and multiple chronic diseases [36-38].

Our results supported the finding that sex differences exist in health-promoting lifestyles [39, 40]. Our data confirmed that women had significantly better health responsibility and nutrition than men. The subscales in which women surpassed men were consistent with the reports by Johnson and Wei et al. [39, 40]. Sexdifference trends have also been demonstrated in the prevalence of obesity over the last few decades in the Asian population. Furthermore, disease vulnerability and an awareness of health differ according to sex; thus, sexspecific public health interventions may be essential in the future [41]. As for women, postmenopausal status is known to be a key risk factor for metabolic alterations and the development of chronic diseases [42]. Our study did not account for menopausal status; therefore, further studies that will consider menopausal status as a factor in the relationship between lifestyle, sex, and chronic diseases are recommended. Our results underscore the necessity of sex-sensitive research and approaches for improved preventive programs for various chronic diseases.

Our results suggest an association between lifestyle and health conditions, implying the possibility to control or alleviate the prevalence of chronic diseases by the modification of health behaviors. These findings could arouse concern about lifestyle behaviors and promote self-assessment of health-promoting lifestyles to the general public. Health promotion and disease prevention programs could be focused on particular dimensions defined by imbalances in the HPLP-II subscales, such as the physical inactivity issue in society reflected by the lowest score in the physical activity subscale.

Some limitations should be considered. The chronic disease statuses were estimated from the beta-testing version of the ARIA for chronic diseases parameters. The study used a noninvasive detection approach based on retinal characteristics, the ARIA, instead of traditional clinical data. Nevertheless, using several diseasespecific retinal characteristics, ARIA provides insights into the clinical interpretation of risk estimation and diseases diagnosis [43]. For instance, in the development of 
CKD, the occurrence of subclinical renal microvascular abnormalities is reflected by specific retinal microvascular abnormalities, including smaller retinal arterioles, larger retinal venules, and the presence of retinopathy [44] which is defined as the presence of one or more microaneurysms or retinal hemorrhages [45]. Previous studies have shown that retinal characteristics not only add value to the clinical differentiation between diseases statuses, such as stroke and CKD [43, 44, 46-48], but can also be ascertained reliably by standardized photographic grading methods using computer-assisted quantification of the retinal characteristics, supporting the validity of the associations between retinal characteristics and diseases [48].

Second, due to the limited resources, the sample size is relatively small. The true differences may not be demonstrated and it may limit inferences about causal relationships between health conditions and healthpromoting lifestyles. With greater resources, a longitudinal design with larger sample size could be applied to investigate the causal relationship between healthpromoting lifestyles and chronic diseases. For the same reason that our resources are limited, participants in this study could not be randomly sampled in all 18 districts in Hong Kong. However, our samples were recruited voluntarily from the general public and they came from community-dwelling backgrounds. Moreover, the prevalence of anemia, CKD and obesity in the sample were not significantly different from those in the general population (Additional file 1); therefore, the sample representativeness was considered acceptable for this study. Further research using a random sampling method is also recommended to have a more representative cohort.

To our knowledge, this study is the first to examine the relationship between obesity, common chronic diseases, and the HPLP-II in Hong Kong Chinese adults, shedding light on the importance of lifestyle factors in East Asian People as they become more westernized. Additionally, instead of using traditional assessment methods like blood tests, this study used an innovative noninvasive diagnostics approach, ARIA, which is easy to perform and useful in the public health management setting.

\section{Conclusion}

In summary, this study demonstrated the physical inactivity issue through the imbalanced HPLP-II subscale score. Moreover, our findings, which revealed lower HPLP-II score in patients with estimated chronic diseases than in healthy individuals, suggest that people with low HPLP-II scores should be concerned about their health. An association between obesity, estimated $\mathrm{CKD}$, and health-promoting lifestyles was noted, indicating a potential role for health-promoting lifestyles in alleviating the risk of obesity and CKD. The study also provided new insights into the relationship between the HPLP-II and other common chronic diseases that warrants further study. Healthcare providers should be involved actively in improving lifestyle factors and modifying barriers in the promotion of health among Hong Kong people of all ages.

\section{Supplementary Information}

The online version contains supplementary material available at https://doi. org/10.1186/s12889-020-09726-x

Additional file 1. Proportion test results of diseases' prevalence in sample and the general population. No significant difference was observed between the prevalence of overall obesity in the study sample and the general population of Hong Kong retrieved from the PHS [2]. Similarly, there was no significant difference between the prevalence of estimated anemia in sample and the worldwide reported by $\mathrm{WHO}$ [49]. The prevalence of estimated CKD in sample was in the same range as that in Asia [50].

Additional file 2. Quadratic effect of the Interpersonal Relationship score predicting BMI. The curve estimation showed an inverted U-shaped relationship between interpersonal relations and BMI. As the BMI increased, the interpersonal relations score increased; beyond a BMI of approximately $23 \mathrm{~kg} / \mathrm{m}^{2}$, the borderline of normal weight, an increase in $\mathrm{BMI}$ was associated with a reduction in the interpersonal relations score.

Additional file 3. Quadratic effect of the Stress Management score predicting WHR. The curve estimation showed an inverted U-shaped relationship between stress management and WHR. As the WHR increased, the stress management score increased; beyond a WHR of approximately 0.9, the borderline of normal weight, an increase in WHR was associated with a reduction in the stress management score.

\section{Abbreviations}

AOR: Adjusted odds ratio; ARIA: Automatic retinal image analysis; BMI: Body mass index; Cl: Confidence interval; CKD: Chronic kidney disease;

CVD: Cardiovascular disease; eGFR: Estimated glomerular filtration rate; HDLC: High-density lipoprotein cholesterol; HPLP-II: Health-Promoting Lifestyle Profile II; LDL-C: Low-density lipoprotein cholesterol; NCD: Non-

communicable disease; PHS: Population Health Survey; TC: Total cholesterol; WHR: Waist-hip ratio

\section{Acknowledgements}

Not applicable.

\section{Authors' contributions}

MMPL and CKMK conceived of the study. YSL analyzed the data and drafted the manuscript. JJWL and KCC helped in the acquisition and analysis of data. YSL drafted the manuscript. MMPL and KCC reviewed the manuscript for important intellectual content. All authors read and approved the final manuscript.

Funding

Not applicable.

\section{Availability of data and materials}

The datasets used and/or analyzed in the current study are available for fulfilling partially of a Master Degree Program of YSL. The datasets generated and/or analysed during the current study are not publicly available due to confidentiality requirements.

\section{Ethics approval and consent to participate}

This study procedure is approved by The Joint Chinese University of Hong Kong - New Territories East Cluster Clinical Research Ethics Committee. Written informed consent was received from all the participates. 


\section{Consent for publication}

Not applicable.

\section{Competing interests}

As the member of the editorial board of the journal, KCC was not involved in the peer review process of this article. Others authors declare that they have no competing interests.

Received: 13 February 2020 Accepted: 18 October 2020

Published online: 28 October 2020

\section{References}

1. WHO/FAO. Noncommunicable diseases. Geneva: World Health Organization; 2018.

2. Chan CHY, Ching R. Announcement of key findings of the 2nd population health survey. HK Department of Health 2017.

3. Social Surveys Section (2) CaSD. Thematic Household Survey Report No.63. HK Census and Statistics Department; 2017.

4. WHO/FAO. Diet, nutrition, and the prevention of chronic diseases. Geneva: World Health Organization; 2003

5. Knowler WC, Barrett-Connor E, Fowler SE, Hamman RF, Lachin JM, Walker EA, et al. Reduction in the incidence of type 2 diabetes with lifestyle intervention or metformin. N Engl J Med. 2002;346(6):393-403.

6. Tuomilehto J, Lindström J, Eriksson JG, Valle TT, Hämäläinen H, llanneParikka P, et al. Prevention of type 2 diabetes mellitus by changes in lifestyle among subjects with impaired glucose tolerance. New Engl J Med. 2001; 344(18):1343-50.

7. Elmer PJ, Grimm R, Laing B, Grandits G, Svendsen K, Vanheel N, et al. Lifestyle intervention: results of the treatment of mild hypertension study (TOMHS). Prev Med. 1995;24(4):378-88.

8. Caligiuri SP, Pierce GN. A review of the relative efficacy of dietary, nutritional supplements, lifestyle, and drug therapies in the management of hypertension. Crit Rev Food Sci Nutr. 2017;57(16):3508-27.

9. Walker SN, Sechrist KR, Pender NJ. Health promotion model - instruments to measure health promoting lifestyle: health-promoting lifestyle profile [HPLP II] (adult version). 1995

10. Peduzzi P, Concato J, Kemper E, Holford TR, Feinstein AR. A simulation study of the number of events per variable in logistic regression analysis. J Clin Epidemiol. 1996;49(12):1373-9.

11. Lee RL, Loke AJY. Health-promoting behaviors and psychosocial well-being of university students in Hong Kong. Public Health Nurs. 2005;22(3):209-20.

12. Brady B, Nies MA. Health-promoting lifestyles and exercise: a comparison of older African American women above and below poverty level. J Holist Nurs. 1999;17(2):197-207.

13. Al-Kandari F, Vidal VL, Thomas D. Health-promoting lifestyle and body mass index among College of Nursing students in Kuwait: a correlational study. Nurs Health Sci. 2008:10(1):43-50.

14. Pischon T, Boeing H, Hoffmann K, Bergmann M, Schulze MB, Overvad K, et al. General and abdominal adiposity and risk of death in Europe. New Engl J Med. 2008;359(20):2105-20

15. WHO Expert Consultation. Appropriate body mass index for Asia populations and its implications for policy and intervention strategies. Lancet. 2004;363:157-63.

16. Organization WH. Waist circumference and waist-hip ratio: report of a WHO Expert consultation, Geneva, 8-11 December 2008. Geneva: World Health Organization; 2008

17. Qiao Q, Nyamdorj R. The optimal cutoff values and their performance of waist circumference and waist-to-hip ratio for diagnosing type II diabetes. Eur J Clin Nutr. 2010;64:23-9.

18. Zee B, Lee J, Li Q. Method and device for retinal image analysis. [Online] United States; 2014. Available from: https://patents.google. com/patent/ US8787638B2/en.

19. Organization WH. Haemoglobin concentrations for the diagnosis of anaemia and assessment of severity. World Health Organization; 2011.

20. Levey AS, De Jong PE, Coresh J, Nahas ME, Astor BC, Matsushita K, et al. The definition, classification, and prognosis of chronic kidney disease: a KDIGO controversies conference report. Kidney Int. 2011;80(1):17-28.

21. National Kidney Foundation. K/DOQI 2012 clinical practice guidelines for the evaluation and management of chronic kidney disease. Kidney Int Suppl. 2013;3(1):S1-S150
22. Millán J, Pintó X, Muñoz A, Zúñiga M, Rubiés-Prat J, Pallardo LF, et al. Lipoprotein ratios: physiological significance and clinical usefulness in cardiovascular prevention. Vasc Health Risk Manag. 2009;5:757-65.

23. Ascaso J, Santos PG, Mijares AH, Rojas AM, Masana L, Millan J, et al. Management of dyslipidemia in the metabolic syndrome. Am J Cardiovasc Drugs. 2007;7(1):39-58

24. Criqui MH, Golomb BA. Epidemiologic aspects of lipid abnormalities. Am J Med. 1998;105(1):48S-57S

25. Fiorito LM, Marini M, Francis LA, Smiciklas-Wright $H$, Birch LL. Beverage intake of girls at age 5 years predicts adiposity and weight status in childhood and adolescence. Am J Clin Nutr. 2009;90:935-42.

26. Moore LL, Bradlee ML, Gao D, Singer MR. Low dairy intake in early childhood predicts excess body fat gain. Obesity (Silver Spring). 2006;14:1010-8.

27. Mota J, Fidalgo F, Silva R, et al. Relationships between physical activity, obesity and meal frequency in adolescents. Ann Hum Biol. 2008;35(1):1-10.

28. Pachucki MC, Goodman E. Social relationships and obesity: benefits of incorporating a Lifecourse perspective. Curr Obes Rep. 2015;4(2):217-23.

29. Nishitani N, Sakakibara H. Relationship of obesity to job stress and eating behavior in male Japanese workers. Int J Obesity. 2006;30(3):528.

30. Foreyt JP, POSTON II WSC. The role of the behavioral counselor in obesity treatment. J Am Diet Assoc. 1998;98(10):S27-30.

31. Valcanti CC, Chaves Ede C, Mesquita AC, Noqueira DA, de Carvalho EC. Religious/spiritual coping in people with chronic kidney disease undergoing hemodialysis. Rev Escola Enfermagem. 2012;46(4):838-45.

32. Fradelos EC, Tzavella F, Koukia E, et al. Integrating chronic kidney disease patient's spirituality in their care: health benefit and research perspectives. Mater Sociomed. 2015;27(5):354-8.

33. Shirvani M, Sadeghi MV, Hosseini SR, Bijani A, Ghadimi R. Does serum lipid profile differ in anemia and non-anemic older subjects? Casp J Intern Med. 2017:8(4):305.

34. Cao W-J, Chen C-S, Hua Y, Li Y-M, Xu Y-Y, Hua Q-Z. Factor analysis of a health-promoting lifestyle profile (HPLP): application to older adults in mainland China. Arch Gerontol Geriatr. 2012;55(3):632-8.

35. Thanavaro JL, Moore SM, Anthony M, Narsavage G, Delicath T. Predictors of health promotion behavior in women without prior history of coronary heart disease. Appl Nurs Res. 2006;19(3):149-55.

36. Kaya F, Unuvar R, Bicak A, Yorganci E, Cinar B, Oz F. Health promoting behaviors of the lecturers and factors determining these behavior. TAF Prev Med Bull. 2008;7(1):59-64.

37. Omisakin FD, Ncama BP. Self, self-care and self-management concepts: implications for self-management education. Educ Res. 2011;2(12):1733-7.

38. Han K, Trinkoff AM, Storr CL, Geiger-Brown J, Johnson KL, Park S. Comparison of job stress and obesity in nurses with favorable and unfavorable work schedules. J Occup Environ Med. 2012:54(8):928-32.

39. Johnson RL. Gender differences in health-promoting lifestyles of African Americans. Public Health Nurs. 2005:22(2):130-7.

40. Wei CN, Harada K, Ueda K, Fukumoto K, Minamoto K, Ueda A. Assessment of health-promoting lifestyle profile in Japanese university students. Environ Health Prev Med. 2012;17(3):222-7.

41. Park B, Lee YJ. Upcoming aging society and Men's health: focus on clinical implications of exercise and lifestyle modification. World J Mens Health. 2020;38:24-31.

42. Newson L. Menopause and cardiovascular disease. Post Reprod Health. 2018:24:44-9.

43. Zee B, Lee J, Li Q, Mok V, Kong A, Chiang L-K, et al. Stroke risk assessment for the community by automatic retinal image analysis using fundus photograph. Qual Primary Care. 2016;24(3):114-24.

44. Yip W, Ong PG, Teo BW, CY-I C, Tai ES, Cheng C-Y, et al. Retinal vascular imaging markers and incident chronic kidney disease: a prospective cohort study. Sci Rep. 2017;7(1):9374.

45. Drobnjak D, Munch IC, Glümer C, Færch K, Kessel L, Larsen M, et al. Relationship between retinal vessel diameters and retinopathy in the Inter99 eye study. J Clin Transl Endocrinol. 2017:8:22-8.

46. Zhuo YY, Wu JM, Kuang L, Qu YM, Zee B, Lee J, Yang ZX. The discriminative efficacy of retinal characteristics on two traditional Chinese syndromes in association with ischemic stroke. Evid Based Complement Alternat Med. 2020:6051831-8.

47. Lau A, Mok V, Lee J, Fan Y, Zeng J, Lam B, Wong A, Kwok C, Lai M, Zee B. Retinal image analytics detects white matter hyperintensities in healthy adults. Ann Clin Transl Neurol. 2018;6(1):98-105. 
48. Couper DJ, Klein R, Hubbard LD, et al. Reliability of retinal photography in the assessment of retinal microvascular characteristics: the atherosclerosis risk in communities study. Am J Ophthalmol. 2002;133(1):78-88.

49. de Benoist B et al., eds. Worldwide prevalence of anaemia 1993-2005. WHO Global Database on Anaemia Geneva, World Health Organization, 2008.

50. Khan YH, Mallhi TH, Sarriff A, Khan AH, Tanveer N. Prevalence of chronic kidney disease in Asia: a systematic review of population-based studies. JCPSP-J COLL PHYSICI. 2018;28(12):960-6.

\section{Publisher's Note}

Springer Nature remains neutral with regard to jurisdictional claims in published maps and institutional affiliations.

Ready to submit your research? Choose BMC and benefit from:

- fast, convenient online submission

- thorough peer review by experienced researchers in your field

- rapid publication on acceptance

- support for research data, including large and complex data types

- gold Open Access which fosters wider collaboration and increased citations

- maximum visibility for your research: over $100 \mathrm{M}$ website views per year

At $\mathrm{BMC}$, research is always in progress.

Learn more biomedcentral.com/submissions 